\title{
UNA APROXIMACIÓN A LAS TEORÍAS Y ENFOQUES SOBRE LA SOCIOLOGÍA DE LA MÚSICA
}

\section{AN APPROXIMATION TO THE THEORIES OF AND APPROACHES TO THE SOCIOLOGY OF MUSIC}

\author{
Miren Pérez Eizaguirre \\ Universidad Autónoma de Madrid \\ mirenperez@hotmail.com
}

Resumen: Este trabajo realiza una recogida de los aspectos más importantes y de manera resumida que se han llevado a cabo sobre la sociología de la música. Para ello, se toman como base los estudios de Hormigos (2008) y Noya (2011) y así aportar una perspectiva sociológica del tema. Del mismo modo, se explican algunos usos y funciones que ha tenido la música a lo largo de la historia. Como conclusión, se señala la importancia de conocer este aspecto de la sociología, tan desconocido para un gran número de personas, y tan importante para entender y definir el hecho musical presente en la vida humana desde que existe el hombre. ${ }^{1}$

Palabras clave: Sociología, música, arte y sociedad, evolución

\begin{abstract}
In a summarized manner, this work carries out a gathering of the most important aspects regarding music sociology. With that purpose, the works of Hormigos (2008) and Noya (2011) are taken as a base to contribute to a sociological perspective of the topic. In the same way, some uses and functions that music has had throughout history are explained. In conclusion, the importance of appreciating this aspect of sociology is emphasized, yet it is so overlooked by a great number of people, when in fact it is fundamentally important to understand and define the presence of music in people lives since the beginning of mans existence.
\end{abstract}

Key words: Sociology, music, art and society, evolution

1 Este texto es parte de la tesis doctoral que la autora presentó en la Universidad Pontificia de Salamanca. 


\section{Introducción}

La música siempre ha desempeñado una función social incluso cuando se expresa su ausencia. El folklore es el conjunto de elementos externos, uno de ellos es la música, que definen el carácter de una comunidad social. Se modifica en función de la época, tendencias ideológicas, cambios sociales y culturales de la sociedad.

La música es, verifica Fubini (2005), un arte típicamente "social», que se ha ido gestando, a lo largo de su historia, conforme a exigencias de carácter extramusical, de acuerdo con unos fines que cumplir, en la esfera pública, muy precisos; y no sólo esto: la ejecución musical implica un gran aparato - instrumentistas, solistas, directores de orquesta, coros, etc. -, es decir, grupos de personas que asumen su función de intermediarios entre los compositores y el público (Fubini, 2005: 163).

La sociología de la música se distingue de otras producciones artísticas por las particularidades de la obra musical (Gallino, 2005). Salvo para un reducido número de especialistas la música puede tener una interpretación subjetiva por ser un sistema de signos ambiguo. Esto provoca que la atribución de las obras musicales a determinados rasgos de estructuras sociales resulte difícil y contradictoria. Por otro lado, el avance de la tecnología ha originado que se puedan reproducir obras perfectas de manera artificial. Sobre todo, la radio, además de la televisión, ha hecho que la música sea un medio de comunicación de masas y la producción artística más difundida en el espacio o en el tiempo. Además, la música ha sido muy utilizada como medio tranquilizador y de distracción en todo tipo de ámbitos de nuestra vida: tiendas, escuelas infantiles, publicidad y aviones, entre otros.

Asimismo, debemos considerar que es el medio de expresión preferido por los movimientos juveniles y se llega a convertir en un comportamiento colectivo. Existe una problemática que plantea la definición de la sociología de la música con respecto a otras artes (Bonnot, 1963). La obra musical posee dos caras, la emocional y la intelectual, lo que podría conducir a definirla dentro de una sociología de la dinámica de los signos. Por otro lado, la obra musical goza de un modo de existencia original. Se encuadra dentro de un tiempo, necesita de un intérprete y está destinada a un público, que puede ser real como el de un concierto o virtual como el de la radio o una discoteca. Es por esto, por lo que se diferencia de otras artes plásticas, ya que se superponen diversos tiempos sociales y psicológicos. "Una sociología especial de la música abriría entonces el camino a investigaciones de sociología de las variables temporales e, incidentalmente, de sociología de los grados de existencia estética" (Bonnot, 1963:352).

Según Francastel (1963), es complicado establecer un estudio sistemático de la sociología en el arte en general, debido a que no se ajusta a una representación mental precisa, si se ciñe al sentido psicológico de dicha afirmación. Por ello, la obra de arte se transforma en un principio para la reflexión del que la observa, la evalúa por partes y juzga el conjunto final.

Para Blacking (2006), la música debe compararse más con la filosofía que con cualquier disciplina de la rama tecnológica. Cada idea novedosa no surge realmente de las ideas previamente expresadas, aunque se encuentren influenciadas por ellas. El compositor refleja sus vivencias y los acontecimientos contemporáneos que le rodean. Para el autor, lo más relevante de una tradición cultural en cualquier época, es la manera en la que los componentes humanos se articulan entre sí. El disfrute artístico se "basa esencialmente en la reacción de nuestras mentes a la forma" (Boas, 1955: 349), y, por ello, las formas están producidas por mentes humanas 
cuyas prácticas de actividad son una suma de patrones culturales adquiridos de expresión. Debido a que estos se adquieren siempre a través de relaciones sociales y las emociones que les asocian,

el factor formador del estilo decisivo en cualquier intento de expresar sentimientos a través de la música ha de ser su contenido social. Si queremos descubrir los principios básicos de organización que afectan a la forma de los patrones musicales, debemos mirar más allá de las convenciones culturales de determinado siglo, determinada sociedad, para buscarlos en las situaciones sociales en las cuales se aplican y a las cuales se refieren" (Blacking, 2006:125).

La existencia de ciertas lagunas según Otto Meyer Serra (1951), se debe a que "los musicólogos no tienen una formación científica como sociólogos así como, por otra parte, los sociólogos, pese a la afición que prevalece entre ellos por la música, no tienen una suficiente base profesional para un conocimiento del arte musical y sus problemas históricos" (Meyer, 1951:59).

Por este motivo, a pesar de la dificultad que conlleva, es necesario realizar un esclarecimiento y travesía, acerca de los diferentes sociólogos que han escrito sobre la música.

\section{La música y la Sociología}

Para realizar un análisis de su complejidad, de las fases y enfoques que han existido entre los sociólogos y la música, es necesario tener presente los trabajos de dos de ellos. El primero es Jaime Hormigos (2008) con su libro, "Música y sociedad. Análisis sociológico de la cultura musical de la posmodernidad". El segundo Javier Noya (2011) con su artículo "Paradigmas y enfoques teóricos en la sociología de la música" importante para plasmar una estructura general sobre el tema. A partir de ahí, añadimos otros aspectos, y aunque existe un artículo posterior (Noya, del Val, y Muntanyola, 2014), tomaremos como referencia el indicado.

\subsection{La importancia de la música en la sociedad}

En la vida cotidiana nos encontramos de manera constante con música. Las diferentes culturas han conseguido ordenar el ruido y crear melodías, ritmos y canciones que han llevado a cabo un papel trascendental en el desarrollo de la humanidad. Si nos remitimos a los cantos de los pueblos primitivos hasta los ritmos más urbanos como el rock, el jazz o el blues han tenido una influencia muy importante en el desarrollo de la sociedad (Hormigos, 2008).

A la hora de entender el hecho musical, de comprender un mensaje de las notas que surgen de un instrumento musical o de percibir el sentido de una canción, debemos saber que las interacciones que se producen entre los sonidos y los individuos son la consecuencia de respuestas aprendidas, patrones culturales y pautas personales, de ahí que una misma canción pueda ser interpretada de otra forma o en función de de las características culturales de quien la aprecia (Hormigos, 2008).

Cada sociedad clasifica los sonidos de acuerdo con la función que cumplen, así encontramos música compuesta para el baile, música ligera, culta, religiosa, música de consumo, etc. Todas las funciones de la música son establecidas por la sociedad, por lo que podemos decir que solamente estaremos al tanto la música y los movimientos sociales que hay alrededor de ella, si conocemos el trasfondo cultural en el que se realiza, ya que cada cultura musical está ajustada a sus propias peculiaridades. 
Además, tiene establecidos procedimientos concretos para dar validez a la música, para incluir o excluir algo dentro o fuera de un género o para establecer etiquetas que auxilien a la interpretación y clasificación del sonido (Hormigos, 2008).

\subsection{El mensaje musical según Jaime Hormigos}

En relación al mensaje musical, Hormigos (2008), lo divide en dos fases: una primera de desarrollo, y la siguiente de consolidación. La primera correspondería con una vertiente subjetiva del mismo, y la segunda, por el contrario con una objetiva. Los autores más significativos de la primera fase son Lalo (, Simmel (2004), Gurvitch (1953), Silbermann (1961), Bloch (1977), Adorno (1949) y Sorokin (1962). De la segunda, Parsons (1991), Riesmann (1981), Becker (1982), Eco (2006), Bordieu (1988) y Morin, (2003).

Tabla1. Las fases del mensaje musical

\begin{tabular}{|c|l|}
\hline \multicolumn{2}{|c|}{ EL MENSAJE MUSICAL } \\
\hline \multicolumn{2}{|c|}{ AUTORES } \\
\hline 1. FASE DE DESARROLLO & 2. FASE DE CONSOLIDACIÓN \\
\hline -Lalo & -Parsons \\
-Simmel & -Riesman \\
-Gurvitch & -Becker \\
-Silbermann & -Eco \\
-Bloch & -Bordieu \\
-Adorno & -Morin \\
-Sorokin & \\
\hline
\end{tabular}

FUENTE: Elaboración propia a partir de Hormigos (2008)

En la fase de desarrollo, la sociología y la estética de la música adoptarán bajo la influencia del paradigma durkheiniano, una orientación claramente sociológica. El primero de ellos, Lalo (1927) estudia la estética musical. Se sitúa en una posición científica y objetivista en la que los condicionantes sociales actúan sobre el individuo. La expresión artística es un fenómeno individual y social, porque para él, lo primero incluye a lo segundo, y esto afecta a la forma. La técnica social y material la condicionaría en mayor grado que la expresión del artista.

Para Simmel (2004), la música es expresión de la sustancia de una sociedad. La diferencia de las distintas artes porque expresa de manera inmediata las ideas, y lo que las otras no pueden expresar: la esencia interior de la voluntad. El autor atribuye a la música la capacidad de alejar al espíritu de lo triste, lo pequeño.

Gurvitch (1953) ve la música como actividad del espíritu individual y social, la sociología de la música se estudia como parte de la "sociología de la civilización", anteriormente denominada como "sociología del espíritu", y que no pretende sustituir a la filosofía, pero provocará que ésta última tenga que recurrir a la sociología.

Dentro del paradigma marxista encontramos a Bloch (1977) para quien el ego y la subjetividad constituyen el eje de la expresión musical. Por ello, 
tras el fin de las ideologías de clase, para las que sólo sirve de decoración, la cultura no experimenta otra pérdida que la de su decoración misma, de la armonización falsamente acabada. La función utópica arranca los usos de la cultura humana de este lecho corrompido de la mera contemplación; y abre así, desde cumbres verdaderamente escaladas, la visión no falseada ideológicamente del contenido de la esperanza humana (Bloch, 1977:180).

En oposición a estos autores nos encontramos con Silbermann (1961), que lleva a cabo un análisis empirista de la música.

Autores que establecen un paralelismo entre música y sociedad también se encuentran en esta fase. Un autor indispensable en la sociología de la música es Adorno (2000), para el que la música y la sociedad están ensambladas por una correspondencia que admite observar un progreso de la música en relación con la evolución social. En referencia al estudio de los cambios de los principales estilos musicales en el tiempo y en el espacio, según Sorokin (1962), las observaciones que realiza indican que el cambio y la creatividad culturales, aparecen en distintos sistemas o sectores, según las épocas, sin que exista un retraso o adelanto uniforme (Sorokin, 1962:1049-1050). En esta división, aparece además el paradigma humanista cuyo campo de estudio se encuentra restringido a la música culta, y en el que aprecia una excesiva preocupación por la estética musical.

Ya en la segunda etapa, la de consolidación, la posguerra abrirá una nueva forma de discurso sociológico sobre la música. En este momento, la sociología de la música adoptará profusas representaciones teóricas y metodológicas desplegadas en otras ramas sociológicas más consolidadas como la sociología del arte, la sociología de la cultura o la sociología de la comunicación. En este caso la división de los autores se realiza según su procedencia.

En EE.UU nos encontramos con Parsons (1991) que destaca por el estudio que hace de la relación entre la música y el subsistema juvenil en el que se asientan las subculturas. En "La muchedumbre solitaria", Riesman (1981) señala las funciones de la música en el proceso de socialización del individuo, poniéndose de manifiesto que la libertad que el individuo posee en la ciudad tiene un precio, el sentimiento de abandono y de soledad en medio de esa muchedumbre. Por su parte, Becker (2008) expone el proceso existente en los mundos del arte. Para ello explica el proceso de fabricación, distribución y consumo de las obras de arte, entre las que se encuentran los discos. Fija la atención no sólo en las obras de arte y el artista, sino también en el equipo de personas y actividades que envuelven la producción artística.

Si nos trasladamos de continente, en Europa, Umberto Eco (1995), realiza un análisis sociológico de la canción de consumo.

Asimismo, Bordieu en 1988 explica la influencia del capital cultural en la reproducción social. Este puede estar inserto en los habitus, que es el elemento necesario para el ingreso a un determinado campo cultural, o en forma de bienes culturales, como instrumentos, cuadros o libros. En el momento en el que un individuo adquiere competencia cultural y aprende a hablar, escribir u oír música, entre otros, revela su origen en pequeños detalles (Bordieu, 1988:75). El análisis de la multidimensionalidad de la canción que realiza Morin en su libro "Sociología" (2003), es de gran importancia. 


\subsection{La sociología de la música según Noya}

Javier Noya toma como punto de partida la distinción entre teoría sociológica que se entiende como "análisis positivo de la realidad social, del Ser, y teoría social o pensamiento crítico, cuestionando la realidad desde valores normativos, el Deber Ser" (Noya, 2011:1.)

Inscritos en los análisis positivos se distinguen los enfoques según el plano en el que operan:

- Macro: grandes estructuras, procesos e instituciones sociales

- Micro: la interacción cara a cara

- Meso: redes y capital social

Según Noya (2011), el "silencio paradójico" es imperante en la sociología de la música. Como resultado del mismo se produce el alejamiento de la música y la sociología, ya que el mito romántico del artista como genio individual separó a los músicos de la sociología, que investigaba regularidades y factores sociales. Asimismo, el elitismo de la música culta, tampoco benefició el acercamiento de los sociólogos al fenómeno musical, problema que se solucionó en parte con la aparición de la música popular de masas. En la actualidad es más sorprendente y llamativo este "paradójico silencio" de la sociología sobre la música dado el nuevo auge que ha cobrado la sociología cultural con el giro postmoderno, atribuyéndolo al iconocentrismo, al que señala como el origen de este silencio, y a la preeminencia que los postmodernos han dado a lo visual sobre lo auditivo. Asimismo, la sociología de la música reciente ha sido el mayor énfasis puesto en el consumo, ya que los hábitos de escucha son más fáciles de catalogar.

Tabla2.Clasificación cronológica de la evolución de la Sociología de la música

\begin{tabular}{|c|c|c|c|c|}
\hline \multicolumn{5}{|c|}{ CLASIFICACIÓN CRONOLÓGICA DE LA EVOLUCIÓN DE LA SOCIOLOGÍA DE LA MÚSICA } \\
\hline CLÁSICOS & $\begin{array}{c}\text { CLÁSICOS CON- } \\
\text { TEMPORÁNEOS }\end{array}$ & $\begin{array}{c}\text { ENFOQUES } \\
\text { MICRO }\end{array}$ & $\begin{array}{c}\text { ENFOQUES } \\
\text { MACRO }\end{array}$ & INCLASIFICABLES \\
\hline - Weber (1921) & - Adorno (1966) & -Eyerman (1998) & $\begin{array}{c}\text {-Silbermann } \\
(1961)\end{array}$ & - Frith (1980) \\
- Simmel (1939) & - Schütz (1971) & -Jamison (1998) & - Blaukopf (1988) & - De Nora (1995) \\
- Sorokin (1960) & - Elías (1991) & -Becker (2008) & - Peterson (1992) & -Small (1999) \\
\hline
\end{tabular}

FUENTE: Elaboración propia a partir de Noya, 2011

El primer grupo con el que nos encontramos es el denominado como Los Clásicos.

La música sí estuvo en los orígenes, debido a la cultura burguesa de una gran mayoría de sociólogos alemanes. Simmel (1939) dedicó unos cuantos ensayos a este campo.

Sin embargo, el mayor exponente de este apartado es sin duda, Weber, el cual escribió entre 1910-1911 el artículo "Fundamentos racionales y sociológicos de la música", publicado en 1921. En este ensayo editado dentro de "Economía y Sociedad" tomó la armonía occidental como ejemplo del proceso de racionalización occidental, y recalcó el análisis del piano como instrumento que manifestaba el cambio social operado en la música. Como ejemplo se puede destacar, que Weber resalta el papel central de la Iglesia en el proceso de ajuste igualitario del canon musical. Según We- 
ber (2015), la música, a pesar de su subjetividad, puede tratarse sociológicamente si se lleva a cabo una racionalización, es decir, se trata como sistema concreto de signos. Asimismo, existe una relación entre la aparición de Gutenberg y la imprenta y la transformación de la música occidental. La música nace en conexión de una serie de hechos no estrictamente musicales. Esta reflexión es de gran valor, ya que establece un vínculo directo entre música y sociedad.

Entre los primeros sociólogos también se puede incluir la figura de Sorokin, (1960) que muestra tres factores que intervienen en la misma:

a. Los seres humanos que piensan, actúan y reaccionan como sujetos de la interacción.

b. Las significaciones, valores y normas, por las cuales los individuos interaccionan, realizándolas e intercambiándolas en el curso de la interacción.

c. Las acciones externas y fenómenos materiales, en su calidad de vehículos o conductores, a través de los cuales son objetivadas, solidificadas y socializadas las significaciones, valores y normas (Sorokin, 1960:59).

Estos sujetos de interacción pueden ser los individuos y se produce una interacción de tipo personal, o los grupos organizados de seres humanos, en los que se lleva a cabo una interacción de tipo grupal.

Si a los fenómenos de interacción humana, les eliminamos los valores significativos, se convierten entonces en simples fenómenos biofísicos. De este modo, la Novena Sinfonía de Beethoven se reduce a "un complejo de sonidos, o más exactamente a una vibración de ondas de aire de cierta longitud y amplitud" (Sorokin, 1960:69). Sin embargo, el componente significativo, puede influir tanto en la naturaleza de los vehículos como en la conducta de los individuos. Por ello, sus propiedades biofísicas se tornen irrelevantes y desempeñen un papel muy pequeño en las propiedades que se les adjudique. Las palabras son como una corriente eléctrica que pasa entre los seres humanos y para Sorokin (1960) la música constituye la segunda forma principal de conductores simbólicos sonoros. Es por su naturaleza más apta para la objetivación y transmisión de sentimientos y emociones, estados de ánimo difíciles de expresar verbalmente, que para la transmisión de ideas o actos. Por ello se utiliza más a menudo para la comunicación emocional que para la intelectual (Sorokin, 1960:79).

Posteriormente nos encontramos con los Clásicos Contemporáneos. La primera figura importante, Norbert Elías (2002), explica la posición contradictoria del compositor situado entre la sociedad burguesa y la cortesana de la época. Asimismo expone cómo puede desenvolverse un músico en una sociedad adversa.

Posteriormente, aparece el fenomenólogo Alfred Schütz (2003), que propone que los músicos pueden relacionarse entre sí cuando interpetan una obra juntos, sin necesidad de comunicación lingüística.

al parecer, toda comunicación posible presupone una relación de mutua sintonización entre el emisor y el receptor de la comunicación. Esta relación se establece por el recíproco compartir el flujo de experiencias del Otro en el tiempo interior, el hecho de vivir juntos un presente vívido, y la experiencia de esto como un Nosotros. Sólo dentro de esta experiencia el comportamiento del Otro adquiere sentido para el copartícipe sintonizado con él, es decir que el cuerpo del Otro y sus movimientos pueden ser y son interpretados como un campo de expresión de hechos dentro de su vida interior (Schütz, 2003: 169). 
Acentúa la importancia del tiempo compartido por compositor, ejecutantes y oyentes. Además inserta el espacio, ya que todos ellos comparten además del lenguaje, las diferentes dimensiones de tiempo simultáneamente. Es lo que denomina como la sincronización del tiempo interior, y el tiempo exterior.

Para Noya (2011), merece una especial atención Adorno (2009), que se refiere a lo que debería ser la Sociología de la música para alguien al que se le pregunta despreocupadamente, del siguiente modo: "Los conocimientos de la relación entre los oyentes de música como seres individualizados, y la música misma" (Adorno, 2009:177). Para intentar darle un rigor empírico a esta materia, comienza analizando los comportamientos típicos que se producen en la sociedad tras la escucha musical.

Antes de hacer una clasificación, quiere dejar claro el arduo camino que supone analizar la música desde la parte subjetiva, y le parece desacertado intentar hacer un estudio generalizado de ello. Explica que los tipos de escucha no son puros y señala la falta de empirismo de estudios de este tipo, en los que se ha de tener mucha precaución, ya que

la dificultad de sentirse seguros científicamente hablando del contenido subjetivo de la experiencia musical, más allá de los indicios más extrínsecos, es casi prohibitiva. El experimento puede alcanzar los grados de intensidad de la reacción, pero apenas los de la calidad. Los efectos al pie de la letra, fisiológicos y mensurables que la música ocasiona-se han suministrado incluso aceleraciones en las pulsaciones- no son en modo alguno idénticos a la experiencia estética de una obra de arte en tanto que obra de arte (Adorno, 2009:180).

La música además de ser utilizada y compuesta con un fin artístico y estético, puede ser vista desde otros ángulos y campos de estudio ya que posee características propias con respecto a otras artes. Sobre la reflexión acerca de la función de la música comienza con la percepción que de la misma tienen los oyentes. Al desconocer el lenguaje, estos solo comprenden retales, y por ello lo califica de segundo lenguaje musical, un residuo de las obras de arte en el hogar de las masas, y expresando la no conveniencia de la separación entre la teoría musical y la teoría social.

Con respecto a la clasificación que hace de los oyentes, en primer lugar se encontraría el experto, que define como el que lleva a cabo una escucha absolutamente adecuada y consciente. En segundo lugar, aparece el buen oyente, que es aquel que percibe más allá del detalle musical y juzga por sí mismo, y después, el consumidor cultural, el coleccionista de discos, el que no tiene límite y puede oscilar desde el compromiso al esnobismo. En tercer lugar, el oyente emocional se aleja de una escucha estructural, en contraposición al oyente resentido o estático-musical que no puede pensar en la subjetividad ni en la expresión. En cuarto lugar, aparece aquel que percibe la música como entretenimiento, y que es el más importante de todos los tipos. Él no tiene en cuenta la función social de la misma, ni si es para otro, ya que únicamente tiene en cuenta cómo es en sí misma.

\subsection{Los enfoques micro}

Dentro de los Enfoques Micro en los que se produce una interacción cara a cara, debemos comenzar nombrando a Howard S. Becker (2008). Músico de jazz antes que sociólogo, analiza, sobre todo, el mundo norteamericano del arte, que presenta diferencias con el europeo. Construye su teoría de los mundos desde la interacción de los artistas, críticos hasta el mundo del arte, que culminan con submundos del arte con reglas específicas. También hace una distinción en cuatro clases de artistas: los profesionales integrados, disidentes, folk, o populares y naif. Se centra en 
asignar poder de acción social al artista y a la obra, así como a las redes de trabajo y cooperación que se encuentran detrás del trabajo artístico. No se detiene en la relación estilo-clase, sino que lo hace en el análisis más profundo de lo que es el arte en general.

Por otro lado Eyerman y Jamison (1998) defienden que "la música de los movimientos sociales transciende las fronteras de uno mismo y envuelve el individuo en una consciencia colectiva" (Eyerman y Jamison, 1998:163). Ambos plantean un "acercamiento cognitivo" a los movimientos sociales, entendidos como formas de actividad mediante las cuales las personas crean nuevos tipos de identidades sociales. Conciben los movimientos sociales como movimientos de creación colectiva que originan identidades para las sociedades. Las organizaciones del movimiento intervienen como fuerzas estructuradoras, generando un espacio de interacción creativa, ampliándose y socializándose. Convirtiéndose, posteriormente, en un espacio público de articulación de intereses que puede afectar a la totalidad de la sociedad (Eyerman y Jamison, 1998).

\subsection{Los Enfoques Macro}

En contraposición, en los Enfoques Macro que se corresponde con las grandes estructuras, procesos e instituciones sociales, existe una corriente funcionalista hasta los años 60. Silbermann (1961), destaca entre los autores de la misma. Desde otra perspectiva diferente, según dicho autor, será comprensible que la determinación conceptual de aquello que es la sociología de la música tenga que quedar todo lo más entendida posible, si ha de poderse expresar como definición en breves palabras (Silbermann, 1961:90). Por ello, se deben tener en cuenta diferentes aspectos a la hora de llevar a cabo su definición. En primer lugar, si la música es un aspecto de la vida humana social, se puede comprender la sociología de la música como la ciencia que se ocupa de entender este aspecto. En segundo lugar, si se admite que la música es una actividad social, la sociología de la música estudia cuáles son los grupos sociales que se reúnen alrededor de una forma musical específica. Asimismo se investigan las funciones de la música, y la evolución de la misma. En tercer lugar, si se toma como referencia la música como centro de las relaciones entre los hombres entonces la sociología de la música se define como:

- El estudio de los efectos de la música sobre la vida social de los individuos.

- El estudio de su influencia en la formación de los grupos.

- El estudio de la evolución y diferenciación de modelos y actitudes sociales por medio de la música.

- El estudio de las instituciones socio- musicales.

- El estudio de formas y factores típicos de organizaciones sociales que influencian la música.

\subsection{La música como un proceso social vivo}

Y por último, en cuarto lugar, si se toma la música como un proceso social vivo y actual, la sociología estudia el proceso en constante evolución, de la interrelación entre música y sociedad.

Junto con la figura de Adorno, a menor escala dentro del marxismo encontramos a Blaukopf (1988), que asevera que la relación entre la estructura de la música y la estructura de la sociedad, es más profunda de lo que comúnmente se supone. 
La Sociología de la música intenta comprender la producción y reproducción de la música en relación con el proceso del desarrollo histórico de la sociedad humana. La persistencia de esta ciencia específica -la Sociología de la música- evidencia que la Musicología como tal no cumple (o al menos no enteramente) esta exigencia de iluminar las motivaciones sociales en los cambios históricos de la música (Blaukopf, 1988:5)

Desde esta perspectiva continuista para Plejanov (1976), la función social es la categoría esencial, que pone de manifiesto el nexo entre la estructura económica de la sociedad y la constitución interna de la música. En Francia, todavía destaca la figura de Bordieu (1988), al que lo que más le interesa es revelar los mecanismos encubiertos de la estructura del campo artístico musical. Esta revelación se consigue indagando en la naturaleza histórica del campo de elaboración artística que, produce la afirmación irrefutable del valor del arte y del poder creador como valor engrandecido del artista.

Dentro del área del consumo nos encontramos con Richard Peterson (2005), sociólogo norteamericano que corresponde a la década de los 80 , y se encarga de estudiar los fenómenos de la producción. Aboga por hacer investigaciones internacionales, al contrario que Bordieu. Expone una teoría que reflexiona sobre las relaciones entre gusto, clase social y estatus (Peterson, 2005). A él podemos atribuir el concepto del "omnivorismo cultural", planteada como una crítica a la teoría de la distinción establecida por Bourdieu.

En sus trabajos más clásicos, exponiendo que los gustos legítimos de las nuevas clases dominantes se determinan, hoy en día, por un amplio abanico de preferencias culturales, con gustos que se amplían desde las artes más refinadas a las expresiones pertenecientes a subculturas populares. Peterson presentó con Simkus, en 1992, un trabajo en el que demostraba que la amplitud de conocimientos culturales no iba asociada necesariamente con clases altas. Años más tarde, llevó a cabo algunas modificaciones, y estableció las siguientes categorías definitivas en su teorización del "omnivorismo cultural" (Fernández y Heikkilä, 2011):

a) "Unívoros de la alta cultura o refinados". Pertenecen a grupos sociales asociados a clases altas y medias altas, cuyos gustos siguen, los valores culturales elitistas dominantes y productores de distinción social.

b) "Los omnívoros de la alta cultura o refinados", "omnívoros" auténticos, cuya diferencia con el primer grupo se encuentra en que además de poseer gusto por la alta cultura, también lo poseen hacia ciertos elementos de la cultura popular. Asimismo, son consumidores activos, y suelen proceder de las clases medias y altas.

c) "Los unívoros de la cultura popular", los "unívoros" auténticos, con un conjunto de aficiones limitado, hábitos de consumo pasivos. Los que socialmente se consideran poseedores del "mal gusto".

d) Los consumidores "omnívoros de la cultura popular", integrada como su propio nombre indica, por consumidores cuyo objeto de consumo reside en su mayoría en la cultura popular, y en menor medida en la alta cultura.

Según Peterson (2005), este fenómeno lleva asociado un mayor respeto y tolerancia hacia el resto de la sociedad, ya que aquellas personas que tengan una mayor apertura en sus gustos musicales, lo reflejarán también en sus relaciones sociales. Este fenómeno es característico del siglo XXI, por el tipo de sociedad imperante, y 
por los medios de difusión y comunicación (televisión, telefonía Internet) que permite acceder a todo tipo de producción cultural.

\subsection{Otros autores}

Por último, dentro de los Inclasificables nos encontramos con Tia DeNora (2000), que es una de las figuras del campo en la actualidad. En sus orígenes, utiliza un enfoque situado entre el marxismo y el análisis weberiano de los estilos de vida de la aristocracia y la burguesía vienesa. La finalidad fue desmontar el mito de Beethoven como héroe burgués, y subrayar la visión contradictoria del artista. Con el tiempo, sin embargo, ha evolucionado hacia planteamientos postmodernos, centrándose en el papel de la música en la vida cotidiana, incluso en su poder terapéutico.

En el campo de la sociología del Rock, Simon Frith (1987) fue uno de los precursores europeos, centrándose en la interacción entre los factores de clase y los culturales en el campo del consumo y de la creación. La música seria es importante porque trasciende las fuerzas sociales. La música popular carece de valor estético porque está condicionada porque es «útil» 0 «utilitaria».

La música popular se considera buena sólo para hacer teoría sociológica con ella. El acierto con el que logramos explicar la consolidación del rock'n'roll o la aparición de la música disco se toman como prueba de su falta de interés estético. Relacionar música y sociedad se convierte así en un cometido distinto en función de la música con la que estemos tratando. Cuando analicemos la música seria, deberemos poner al descubierto las fuerzas sociales que se ocultan tras los discursos sobre valores «trascendentes»; al analizar el pop, deberemos tornar seriamente en consideración los valores desdeñados en los discursos sobre funciones sociales" (Frith y Horne, 1987:413). El autor descarta la idea en la que la música popular está sometida a los gustos colectivos determinados por la clase, el género y el grupo étnico. Reflexiona acerca del impacto que la música produce sobre los personas, y lo atribuye a cuestiones individuales, más que de la colectividad.

Categoriza en cuatro funciones los usos más significativos de la música pop, para que se comprenda cómo se realizan los juicios de valor en este tipo de música. El primero de ellos es el uso que realizamos de la misma en busca de nuestra identidad. Se produce la identificación con otras personas a las que también les gusta ese mismo género y el placer que sentimos en dicha escucha. Además surge la expresión clara que reflejamos cuando algo no nos gusta. La segunda función social de la música sería suministrar una vía para gestionar la correspondencia entre la vida emocional pública y la privada.

La mayoría de la música popular occidental y no occidental del siglo XX, está compuesta de canciones de amor, debido a la necesidad de expresión de nuestros sentimientos de manera que no resulte incómoda. La tercera función de la música popular, es la de organizar el sentido del tiempo, ya que la música sirve para intensificar el presente, señalando el impacto físico de la música. Un ejemplo de ello sería la música "dance" ya que los clubes y las fiestas proveen de un entorno social que parecen definidos únicamente por la medida del tiempo que proporciona la música (las pulsaciones por minuto), el cual escapa al tiempo real que transcurre ahí afuera.

Otro ejemplo obvio de esta función sería remarcar el hecho de que las canciones y las melodías son a menudo la clave para recordar cosas que sucedieron en el pasado. A medida que nos hacemos adultos usamos menos la música. Las canciones más significativas para la mayoría de las personas, son aquellas que se escuchaban en la época adolescente, por lo que ser «joven» se define a partir de la música. Este 
hecho es socialmente importante no porque muestre la experiencia de los jóvenes, sino porque precisa lo que es la "juventud". La cuarta y última función de la música popular se refiere que es algo que se posee, porque al tener determinada música, la convertimos en una parte de nuestra propia identidad y la incorporamos a la percepción de nosotros mismos.

En el aspecto del análisis práctico de la música, se encuentra Cristopher Small (1999), que lo que denomina con el término "musicar", un ritual en el espacio social (Small, 1999). La institucionalización de la música culta occidental es criticable, y es necesario no llevar a cabo una definición abstracta y compleja de la música. Un lenguaje común a todos los seres humanos, enfatizando en la acción de llevar a cabo la música, más que en el objeto, es decir la partitura. Una actuación musical es mucho más compleja que la limitación que lleva consigo el estudio únicamente de la misma y su impacto sobre un determinado oyente. De ahí que la palabra música no pueda ser un sustantivo, sino un verbo, "musicar".

Estudios más recientes (Noya, Del Val y Muntanyola, 2014) vuelven a revisar esta clasificación distinguen tres niveles dentro de la sociología de la música: macro, meso y micro.

\section{Elementos comunes existentes entre los estudios}

En la sistematización que ambos investigadores establecen (Hormigos, 2008; Noya, 2011), hay elementos comunes.

Tabla 3.Resumen autores comunes Hormigos (2008) y Noya (2011)

\begin{tabular}{|c|c|c|}
\hline AUTORES COMUNES & HORMIGOS (2008) & NOYA(2011) \\
\cline { 1 - 1 } Simmel & \multirow{2}{*}{ Fase desarrollo } & Clásicos \\
\cline { 1 - 1 } Silbermann & & Enfoques macro \\
\cline { 1 - 1 } Adorno & & Enfoques macro \\
\cline { 1 - 1 } Sorokin & & Clásicos \\
\hline Becker & Fase consolidación & Enfoques micro \\
\hline
\end{tabular}

FUENTE: Elaboración propia a partir de Hormigos (2008) y Noya (2011)

Se observa que a clasificación que realiza Hormigos (2008) se basa en el tipo de mensaje musical. En la fase de desarrollo y la subjetividad del mismo nos encontramos a un grupo de autores que también selecciona Noya (2011). Y únicamente pertenecen a dos grupos de su clasificación como son los Clásicos y los enfoques Macro. Recordemos que estos últimos relacionan el enfoque con las instituciones, los procesos sociales. Se establece siempre una relación entre la evolución de la música y la sociedad.

En cambio, Becker que es el único autor coincidente de la fase de consolidación, es decir, del componente objetivo del mensaje musical, se encuentra dentro del Enfoque micro según Noya (2011). Este autor habla del proceso que envuelve a la producción artística, lo que envuelve al proceso. 


\section{La música como elemento transformador de las relacio- nes sociales}

La música es una de las artes con un impacto más directo sobre las personas y siempre ha desempeñado una función social. El folklore es el conjunto de elementos externos (uno de ellos es la música), que definen el carácter de una comunidad social. Este se modifica en función de la época, tendencias ideológicas, cambios sociales y culturales en la sociedad. Es importante recordar que

la socialización es el proceso por cuyo medio la persona aprende e interioriza, en el transcurso de su vida, los elementos socio-culturales de un medio ambiente, los integra a la estructura de su personalidad, bajo la influencia de experiencias y de agentes sociales significativos, y se adapta así al entorno social en cuyo seno debe vivir" (Rocher, 1996, p.34).

El disfrute artístico se "basa esencialmente en la reacción de nuestras mentes a la forma” (Boas, 1955: 349), y, por ello, las formas están producidas por mentes humanas cuyas prácticas de actividad son una suma de patrones culturales adquiridos de expresión. Debido a que estos se adquieren siempre a través de relaciones sociales y las emociones que les asocian, "el factor formador del estilo decisivo en cualquier intento de expresar sentimientos a través de la música ha de ser su contenido social" (Blacking, 2006: 125). El fenomenólogo Alfred Schütz (2003), propone que los músicos pueden relacionarse entre sí cuando interpretan una obra juntos, sin necesidad de comunicación lingüística.

La revisión teórica realizada en la que se otorga un papel socializador a la música, coincide con una de las funciones que también se le asigna al uso de la misma desde su vertiente terapéutica, la musicoterapia.

El conocimiento de todos estos conceptos sirve de gran ayuda a la hora de centrar la atención en ella. Según la definición de la Federación Mundial de Musicoterapia (WFMT, 2011):

La Musicoterapia es el uso profesional de la música y sus elementos como una intervención en ambientes médicos, educativos y cotidianos con individuos, grupos, familias o comunidades, buscando optimizar su calidad de vida y mejorar su salud y bienestar físico, social, comunicativo, emocional, intelectual y espiritual. La investigación, la práctica, la educación y la formación clínica en la Musicoterapia están basados en estándares profesionales según los contextos culturales, sociales y políticos.

En dicha definición, se alude al contexto social propio de toda relación humana, que en las relaciones terapéuticas es de máxima importancia. Por ello, el conocimiento de los aspectos relacionados con la sociología de la música, puede ser de gran utilidad a la hora de estar al tanto sobre qué aspectos sociales son importantes en el desarrollo de la musicoterapia como disciplina. Existen diversos estudios en los que queda patente la influencia de la musicoterapia en la transformación de las relaciones sociales con diversos colectivos: adolescentes en riesgo social (Pérez Eizaguirre, 2013); pacientes pertenecientes al área de psiquiatría (Gold, Solli y Krüger 2009); niños que presentan trastornos del espectro autista (Edgerton, 1994), entre otros.

En todos estos procesos se alude a la música como el medio con el que se establecen otras vías de comunicación, y se le atribuye las características que en sociología de la música también se le dan, al tratarse esta como un lenguaje, y un medio de interacción y de expresión. 


\section{Conclusiones}

En definitiva, la música abarca todos los aspectos de la vida (Waterman, 1956), y se utiliza en todo el mundo para acompañar a otras actividades. La línea antropológica iniciada por Merriam (2001) es apoyada también por John Blacking (2006) con su libro "¿Hay música en el hombre?”, aunque con bastantes matices, ya que no hace una clasificación de las funciones, y tampoco le preocupa las funciones que la misma pueda realizar, sino qué es la música. Es interesante la reflexión que hace Blacking (2006) acerca de que la música como producto de la conducta de grupos humanos, ya que la define la como "sonido humanamente organizado" (Blacking, 2006:109).

En relación a estas ideas nos hemos encontrado con la clasificación tan clara de estos investigadores Hormigos, 2008; Noya, 2011).

Hormigos (2008) lleva a cabo una relación directa entre música y sociedad. Del mismo modo, establece el mensaje musical como el punto de referencia para su ordenación, diferenciando la vertiente objetiva o subjetiva del mismo. Si nos detenemos en la primera nos encontramos con la fase de desarrollo y los siguientes autores; Lalo (1927) estudia la estética musical, y se sitúa en una posición científica y objetivista en la que los condicionantes sociales actúan sobre el individuo; Simmel (2004), define la música como expresión de la sustancia de una sociedad; Gurvitch (1953) ve la música como actividad del espíritu individual y social y la sociología de la música como parte de la "sociología de la civilización; Silbermann (1961), lleva a cabo un análisis empirista de la misma; Bloch (1977) defiende que el ego y la subjetividad constituyen el eje de la expresión musical; Adorno (1949) expone que música y sociedad están ensambladas por una correspondencia que admite observar un progreso de la música en relación con la evolución social y Sorokin (1962) cuyas observaciones indican que el cambio y la creatividad culturales aparecen en distintos sistemas o sectores, según las épocas, sin que exista un retraso o adelanto uniforme. En la segunda, la fase de consolidación, aparecen los siguientes autores. Parsons (1991) destaca por el estudio que hace de la relación entre la música y el subsistema juvenil en el que se asientan las subculturas. En "La muchedumbre solitaria", Riesman (1981) señala las funciones de la música en el proceso de socialización del individuo, Por su parte, Becker (2008) expone el proceso existente en los mundos del arte. Umberto Eco (1995), realiza un análisis sociológico de la canción de consumo. Asimismo, Bordieu (1988) explica la influencia del capital cultural en la reproducción social. Por último nos encontramos con el análisis de la multidimensionalidad de la canción que realiza Morin (2003).

Por otro lado, Noya (2011) se basa en el enfoque de los análisis positivos según el plano en el que operan. Diversos autores demostraron que la música sí estuvo en los orígenes, debido a la cultura burguesa de una gran mayoría de sociólogos alemanes. Simmel (1939) dedicó unos cuantos ensayos a este campo. Según Weber (2015), la música, a pesar de su subjetividad, puede tratarse sociológicamente si se lleva a cabo una racionalización, es decir, se trata como sistema concreto de signos. Entre los primeros sociólogos también se incluye la figura de Sorokin, (1960).

Posteriormente nos encontramos con los Clásicos Contemporáneos. La primera figura importante, Norbert Elías (2002), explica la posición contradictoria del compositor situado entre la sociedad burguesa y la cortesana de la época. Adorno (2009), intenta darle un rigor empírico a esta materia, por lo que comienza analizando los comportamientos típicos que se producen en la sociedad tras la escucha musical. Del mismo modo, aparece el fenomenólogo Alfred Schütz (2003), que propone que los músicos 
pueden relacionarse entre sí cuando interpretan una obra juntos, sin necesidad de comunicación lingüística.

Dentro de los Enfoques Micro en los que se produce una interacción cara a cara, Howard S. Becker (2008), músico de jazz antes que sociólogo, analiza, sobre todo, el mundo norteamericano del arte, que presenta diferencias con el europeo.

Por otro lado Eyerman y Jamison (1998) plantean un "acercamiento cognitivo" a los movimientos sociales, entendidos como formas de actividad mediante las cuales las personas crean nuevos tipos de identidades sociales.

En contraposición, en los Enfoques Macro que se corresponde con las grandes estructuras, procesos e instituciones sociales, existe una corriente funcionalista hasta los años 60. Silbermann (1961), destaca entre los autores de la misma.

Y por último, en cuarto lugar, si se toma la música como un proceso social vivo y actual, la sociología estudia el proceso en constante evolución, de la interrelación entre música y sociedad.

Junto con la figura de Adorno, a menor escala dentro del marxismo encontramos a Blaukopf (1988), que asevera que la relación entre la estructura de la música y la estructura de la sociedad, es más profunda de lo que comúnmente se supone. Para Plejanov (1976), la función social es la categoría esencial, que pone de manifiesto el nexo entre la estructura económica de la sociedad y la constitución interna de la música. En Francia, todavía destaca la figura de Bordieu (1988), al que lo que más le interesa es revelar los mecanismos encubiertos de la estructura del campo artístico musical. Dentro del área del consumo Richard Peterson (2005), se encarga de estudiar los fenómenos de la producción.

Por último, dentro de los Inclasificables nos encontramos con Tia DeNora (2000), que es una de las figuras del campo en la actualidad. La finalidad fue desmontar el mito de Beethoven como héroe burgués, y subrayar la visión contradictoria del artista. Con el tiempo, sin embargo, ha evolucionado hacia planteamientos postmodernos, centrándose en el papel de la música en la vida cotidiana, incluso en su poder terapéutico. En el campo de la sociología del Rock, Simon Frith (1987) fue uno de los precursores europeos, centrándose en la interacción entre los factores de clase y los culturales en el campo del consumo y de la creación. En el aspecto del análisis práctico de la música, se encuentra Cristopher Small (1999), y lo que denomina con el término "musicar", un ritual en el espacio social.

Un término de gran importancia es el "silencio paradójico" ya que en el siglo XIX el músico del Romanticismo, en el que imperaba la individualidad, separó a los músicos de la Sociología. Además el elitismo del la música culta supuso un problema para los sociólogos, hasta la aparición de la música popular hacia 1950.

En ambos estudios se observa que la sociología de la música se encontró durante un largo tiempo inscrita en el componente subjetivo del mensaje. Esto se produce de manera paralela con aquellos enfoques como el Macro o el llevado a cabo por los Clásicos en el que se establece una relación directa entre la evolución de la música y la sociedad, y las influencias recíprocas entre unas y otras. Desde aquí se produce un salto a autores como Becker (2008) que centra su atención en la producción musical. En todo lo que eso supone, todo lo que le rodea, coincidiendo con la parte objetiva del mensaje musical.

El "silencio paradójico" existente nos hace plantearnos el por qué de la imposibilidad descrita anteriormente, con la que se encuentran los sociólogos. La etapa anterior, el 
Clasicismo del siglo XVIII, con la decadencia de Mozart como mejor ejemplo, hacía necesaria una reconversión del público, un nuevo planteamiento de la música como arte por el que había que para una entrada. Si los autores no hubiesen optado por ese individualismo, nunca se hubiera llegado a la libertad compositiva, a la existencia de un nuevo público surgido de la nueva clase social. Todo ello se reflejó en la aparición del piano, el instrumento individualista por excelencia ¿Estaba tan separada la sociedad de la música? Nos es difícil verlo así, ya que parece existir de nuevo un paralelismo claro entre música y sociedad. Nos suscita una pregunta sin respuesta este vacío sociológico.

Lo realmente importante de una obra musical, se encuentra en el hecho de que las personas quieran escucharla o interpretarla, si no, carece de sentido, dotando de este modo de una función social a la música, más que una estética. La música no es un lenguaje, sino que su semejanza con el mismo se encuentra en su capacidad para comunicar, solamente a aquellos que pueden entenderlo, y su condicionamiento cultural. Una pieza musical servirá para comprender los patrones culturales de una sociedad. Ahí radica la enorme importancia de conocer los aspectos fundamentales de la sociología de la música, y de un modo más particular hacer llegar a los músicos esta visión tan necesaria para poder desarrollar su profesión de manera más correcta. Si le damos la importancia y el valor social que tiene la música, pondremos en palabras algo de lo que todos somos conscientes.

Si además, no olvidamos el aspecto terapéutico que la música posee, todos estos aspectos relacionados con la sociología de la música adquieren un valor más relevante. Porque conocer este valor social y este análisis, enriquece el trabajo de los musicoterapeutas, extensible del mismo modo, a todos aquellos profesores que se dedican al aspecto pedagógico de la enseñanza de la música. Este campo tan poco conocido de la sociología, se presenta de gran importancia a la hora de enriquecer la visión sobre el aspecto social que posee la música.

\section{Referencias bibliográficas}

Adorno, T. (2009). Disonancias. Introducción a la sociología de la música.

Madrid: Akal.

Adorno, T. W. (2000). Sobre la música. Barcelona: Universidad Autónoma de Barcelona.

Becker, H. S. (2008). Los Mundos del Arte. Sociología del trabajo artístico. Buenos Aires: Prometeo libros.

Blacking, J. (2006). ¿Hay música en el hombre? Madrid: Alianza Editorial.

Blaukopf, K. (1988). Sociología de la música. Madrid: Real Musical.

Bloch. (1977). El principio esperanza. Madrid: Aguilar.

Boas, F. (1955). Primitive Art. New York: Dover Press.

Bonnot, R. (1963). "Sociología de la música”. En G. Gurvitch eds.: Tratado de sociología. 350- 351 Buenos Aires: Editorial Kapelusz.

Bordieu, P. (1988). La distinción. Criterio y bases sociales del gusto. Madrid: Taurus.

DeNora, T. (1995). Beethoven and the Construction of a Genius. Berkeley: University of California Press 
DeNora, T. (2000). Music in everyday life. Cambridge: Cambridge University Press.

Eco, U. (1995). Apocalípticos e integrados. Barcelona: Tusquets.

Edgerton, C. L. (1994). The effect of improvisational music therapy on the communicative behaviors of autistic children. Journal of music therapy, 31(1), 31-62. DOI:10.1093/ $\mathrm{jmt} / 31.1 .31$

Elias,N., Fernández-Villanueva, M., y Strunk, O. (2002). Mozart: Sociología de un genio. Madrid: Ediciones Península.

Eyerman, R., y Jamison, A. (1998). Music and Social Movements: Mobilizing Traditions in the Twentieth Century. Cambridge: Cambridge University Press.

Fernández Rodríguez, C. J., y Heikkilä, R. (2011). "El debate sobre el omnivorismo cultural. Una aproximación a nuevas tendencias en Sociología del Consumo". Revista Internacional de Sociología, 69(3): 585-606. DOI: 10.3989/ris.2010.04.15

Francastel, P. (1963). "Problemas de la sociología del arte". En G. Gurvitch eds.: Tratado de Sociología. 327-350. Buenos Aires: Editorial Kapelusz.

Frith, S. (1980). Sociología del rock. Madrid: Júcar

Frith, S. (1988). "El arte frente a la tecnología. El extraño caso de la música popular". Papers. Sociología, 29: 178-196. DOI: 10.5565/rev/papers/v29n0.1465.

Frith, S., y Horne, H. (1987). Art Into Pop. Londres: Methuen.

Fubini, E. (2005). "La Estética y la Sociología de la Música”. En E. Fubini eds:La estética musical desde la antigüedad hasta el siglo XX. 385-425.Madrid: Alianza.

Gallino, L. (2005). Diccionario de sociología. México: Siglo Veintiuno editores.

Gold, C., Solli, H. P., Krüger, V., y Lie, S. A. (2009). Dose-response relationship in music therapy for people with serious mental disorders: Systematic review and meta-analysis. Clinical psychology review, 29(3), 193-207. DOI: 10.1016/j.cpr.2009.01.001

Gurvitch, G. (1953). La Vocación actual de la sociología: Hacia una sociología diferencial. México: Fondo de Cultura Económica.

Herskovits, M.J. (1948). Man and his Works: The Science of Cultural Anthropology. New York: Knopf.

Hormigos, J. (2008). Música y sociedad, Análisis sociológico de la cultura musical de la posmodernidad. Madrid: Fundación Autor.

Lalo, C. (1927). Bosquejo de una estética musical científica. Madrid: Daniel Jorro.

Merriam, A. P. (2001). “Usos y Funciones de la Música”. En F. Cruces coord.: Las culturas musicales: lecturas de etnomusicología. 275-296. Madrid: Editorial Trotta.

Meyer Serra, O. (1951). "Problemas de una Sociología de la Música". Revista Mexicana de Sociología, 13: 23-34.

Morin, E. (2003). Sociología. Barcelona: Anthropos.

Noya, J. (2011). "Paradigmas y enfoques teóricos en la sociología de la música". Grupo MUSYCA. Madrid: Universidad Complutense.

Noya, J., del Val, F. y Muntanyola, D. (2014). "Paradigmas y enfoques teóricos en la sociología de la música". Revista Internacional de Sociología, 72(3): 541-562. DOI: 10.3989/ ris.2013.03.23 
Noya, J., del Val, F., Pérez-Colman, C. M. (2014): “¿Autonomía, sumisión o hibridación sonora? La construcción del canon estético del pop-rock español”, Revista Española de Investigaciones Sociológicas, 145: 147-180. DOI: 105477/cis/reis.145.147

Parsons, T. (1991). Social System. Nueva York: Taylor \& Francis Group.

Pérez Eizaguirre, M. (2013) La influencia de la musicoterapia en adolescentes en situación de riesgo social. Tesis doctoral. Madrid: Universidad

Pontificia de Salamanca.

Peterson, R. A. (2005). "Problems in Comparative Research: The Example of Omnivorousness." Poetics 33: 257-282. DOI: 10.1016/j.poetic.2005.10.002

Peterson, R. A. y Simkus, A. ( 1992). "How Musical Tastes Mark Occupational Status Groups". En M. Lamont y M. Fournier eds.: Cultivating Differences. 152-186. Chicago: University of Chicago Press.

Plejanov, G. W. (1976.). Cuestiones fundamentales del marxismo. Viena y Berlín.México: Editorial Fontamara.

Riesman, D. (1981). La muchedumbre solitaria. Barcelona: Paidós Ibérica.

Rocher, G. (1996). Introducción a la sociología general. Editorial Herder. Barcelona.

Schütz, A. (2003). Estudios sobre teoría social: Escritos II. Buenos Aires: Amorrortu.

Silbermann, A. (1961). Estructura social de la música. Madrid: Taurus.

Simmel, G. (1939). Sociología: estudios sobre las formas de socialización. Buenos Aires: Espasa-Calpe.

Small, C. (1999). Música, sociedad, educación. Madrid: Alianza.

Schütz, A. 1971. "Making music together. A study in social relationship." Pp. 169-178 en Collected papers. II, Studies in social theory. The Hague: Martinus Nijhoff.

Sorokin, P. (1960). Sociedad, cultura y personalidad: su estructura y su dinámica: sistema de sociología general. Madrid: Aguilar.

Sorokin, P. (1962). Dinámica social y cultural. Coruña: Instituto de Estudios Políticos.

Waterman, R. (1956). "Music in Australian aboriginal culture-some sociological and psychological implications". En T. Gaston eds.: Music Therapy. Kansas: Lawrence. 40-9.

Weber, M. (2015). Los fundamentos racionales y sociológicos de la música. Madrid: Tecnos. 